\title{
A Population Pharmacokinetic Model of Oral Docetaxel Coadministered With Ritonavir to Support Early Clinical Development
}

The Journal of Clinical Pharmacology 2020, 60(3) 340-350

(c) 2019, The American College of Clinical Pharmacology DOI: $10.1002 / j c p h .1532$

\author{
Huixin Yu, PhD', Julie M. Janssen, PharmD', Emilia Sawicki, PhD', J. G. Coen van \\ Hasselt, PhD', Vincent A. de Weger, MD, PhD', Bastiaan Nuijen, PharmD, PhD', \\ Jan H. M. Schellens, MD, PhD², Jos H. Beijnen, PharmD, PhD ${ }^{1,2}$, \\ and Alwin D. R. Huitema, PharmD, PhD ${ }^{1,3}$
}

\begin{abstract}
Oral administration of docetaxel is an attractive alternative for conventional intravenous (IV) administration. The low bioavailability of docetaxel, however, hinders the application of oral docetaxel in the clinic. The aim of the current study was to develop a population pharmacokinetic (PK) model for docetaxel and ritonavir based on the phase I studies and to support drug development of this combination treatment. PK data were collected from I9I patients who received IV docetaxel and different oral docetaxel formulations (drinking solution, ModraDoc00I capsule, and ModraDoc006 tablet) coadministered with ritonavir. A PK model was first developed for ritonavir. Subsequently, a semiphysiological PK model was developed for docetaxel, which incorporated the inhibition of docetaxel metabolism by ritonavir. The uninhibited intrinsic clearance of docetaxel was estimated based on data on IV docetaxel as $1980 \mathrm{~L} / \mathrm{h}$ (relative standard error, I I\%). Ritonavir coadministration extensively inhibited the hepatic metabolism of docetaxel to $9.3 \%$, which resulted in up to 12 -fold higher docetaxel plasma concentrations compared to oral docetaxel coadministered without ritonavir. In conclusion, a semiphysiological PK model for docetaxel and ritonavir was successfully developed. Coadministration of ritonavir resulted in increased plasma concentrations of docetaxel after administration of the oral formulations of ModraDoc. Furthermore, the oral ModraDoc formulations showed lower variability in plasma concentrations between and within patients compared to the drinking solution. Comparable exposure could be reached with the oral ModraDoc formulations compared to IV administration.
\end{abstract}

Keywords

docetaxel, ModraDoc, oral, population PK, ritonavir

Docetaxel is a widely used anticancer agent acting by inhibition of mitosis. It is approved for the treatment of breast cancer, prostate cancer, non-small cell lung cancer, head and neck cancer, and gastric cancer. Docetaxel is most commonly administered as a 3-weekly 1-hour infusion, although it has been shown that onceweekly administration is associated with comparable efficacy, while incidence of neutropenia is reduced. ${ }^{1,2}$ A weekly schedule is infrequently used, most likely due to inconvenience for the patient associated with weekly clinic visits. An oral formulation of docetaxel would allow patients to receive docetaxel at home, thereby reducing the burden for patients and costs. In addition, oral administration would avoid the regularly observed infusion reactions, induced by the formulation additives polysorbate 80 and ethanol. ${ }^{3}$

After oral administration of docetaxel, low bioavailability and wide inter- and intrapatient variability in systemic exposure has been observed. In the gut and liver, docetaxel is excreted by the P-glycoprotein (ABCB1) efflux transporter and metabolized by cytochrome P450 3A4 (CYP3A4) into inactive metabolites. ${ }^{4}$ Previously, we have shown in a proof-of-concept study that coadministration of the CYP3A inhibitor ritonavir results in a strong boost of the systemic exposure of oral docetaxel. ${ }^{5}$ In this study, the intravenous (IV) docetaxel formulation was ingested orally as a drinking solution. Further, a solid dispersion capsule formulation, ModraDoc001, was developed and clinically evaluated with different dose levels of ritonavir. ${ }^{6}$ Subsequently, a further improved

\footnotetext{
'Department of Pharmacy \& Pharmacology, Netherlands Cancer Institute-Antoni van Leeuwenhoek, Amsterdam, The Netherlands

${ }^{2}$ Utrecht Institute of Pharmaceutical Sciences, Utrecht University, Utrecht, The Netherlands

${ }^{3}$ Department of Clinical Pharmacy, University Medical Center Utrecht, Utrecht University, Utrecht, The Netherlands
}

Submitted for publication I5 August 2019; accepted 20 September 2019.

\section{Corresponding Author:}

Julie M. Janssen, PharmD, Department of Pharmacy \& Pharmacology Netherlands Cancer Institute-Antoni van Leeuwenhoek Plesmanlaan 121 1066 CX Amsterdam, The Netherlands Email: ju.janssen@nki.nl 
Table I. Overview of Included Clinical Studies

\begin{tabular}{|c|c|c|c|c|}
\hline & Study I (5) & Study $2(6,11,12)$ & Study 3a (14) & Study 3b (7) \\
\hline \multicolumn{5}{|l|}{ Number of patients } \\
\hline Total & 37 & 100 & 48 & 6 \\
\hline Intravenous administration docetaxel & 32 & 19 & $\ldots$ & $\ldots$ \\
\hline Oral docetaxel formulation of ModraDoc00I capsule & $\ldots$ & 72 & 17 & 6 \\
\hline Oral docetaxel formulation of ModraDoc006 tablet & $\ldots$ & 18 & 28 & $\ldots$ \\
\hline Oral docetaxel formulation of drinking solution & 25 & 13 & $\ldots$ & $\ldots$ \\
\hline \multicolumn{5}{|l|}{ Docetaxel } \\
\hline Oral dose levels (mg/day) & 10,100 & $20,30,40,60,80$ & $40,50,60,80$ & 40 \\
\hline Intravenous dose levels & $100 \mathrm{mg} / \mathrm{m}^{2}$ & $20 \mathrm{mg}$ & $\ldots$ & $\ldots$ \\
\hline Dosing time $(\mathrm{h})$ & $\mathrm{t}=0, \mathrm{t}=\mathrm{I}$ & $\mathrm{t}=0$ & $\mathrm{t}=0,7$ & $\mathrm{t}=0$ \\
\hline \multirow[t]{4}{*}{ Formulation } & Intravenous & Intravenous & ModraDoc00I & ModraDoc00I \\
\hline & Drinking solution & Drinking solution & ModraDoc006 & \\
\hline & & ModraDoc00I & & \\
\hline & & ModraDoc006 & & \\
\hline Pharmacokinetic data & Yes & Yes & Yes & Yes \\
\hline \multicolumn{5}{|l|}{ Ritonavir } \\
\hline Dose (mg/day) & 0,100 & $0,100,200$ & 200 & 100,200 \\
\hline Dosing time $(\mathrm{h})$ & $\mathrm{t}=0$ & $\mathrm{t}=0$ & $t=0,7$ & $\mathrm{t}=0$ \\
\hline \multirow[t]{2}{*}{ Ritonavir formulation } & Capsules & Capsules & Tablets & Tablets \\
\hline & & Tablets & & \\
\hline Pharmacokinetic data & No & Yes & Yes & Yes \\
\hline
\end{tabular}

solid dispersion tablet formulation, ModraDoc006, was developed and evaluated similarly. ${ }^{7}$

Modeling and simulation can be used to support clinical development. ${ }^{8}$ Previously, we described how modelling and simulation was used to bridge oral docetaxel exposure of the preclinical and the clinical setting, ${ }^{9}$ and to quantitatively study the effect of inhibition of CYP3A4 on docetaxel pharmacokinetics (PK) after oral administration of the IV formulation (drinking solution). ${ }^{10}$ These models, however, did not include the PK of the dedicated oral formulations (ModraDoc001 and ModraDoc006) that were developed thereafter, and also did not include PK data of ritonavir, which was not yet available at that time. However, an integrated docetaxel-ritonavir model is needed to compare different dosing regimens of docetaxel and different oral docetaxel formulations to support decision making in the clinical development.

The objectives of the current analysis were to update a previously developed, integrated, semiphysiological PK model for docetaxel ${ }^{10}$ with data from the novel formulations and by including ritonavir PK data. Subsequently, the model was used to support clinical development of the combination of oral docetaxel and ritonavir.

\section{Methods}

Clinical Studies

All available PK data from clinical studies evaluating the different formulations of docetaxel including the IV formulation administered intravenously and orally, and the oral solid dispersion formulations ModraDoc001 and ModraDoc006, were included. An overview of the different clinical studies is provided in Table 1. In the following sections, the studies are further summarized.

Study I. Study 1 was a proof-of-concept study evaluating ritonavir as a booster of oral docetaxel. Docetaxel was administered intravenously at a dose of $100 \mathrm{mg} / \mathrm{m}^{2}$ or as a drinking solution at a single dose of 10 or $100 \mathrm{mg}$ in combination with ritonavir soft gel capsules (Norvir; Abbott Laboratories, Abbott Park, Illinois) at a dose of $100 \mathrm{mg}$. For a detailed description of this study, see Oostendorp et al. ${ }^{5}$

Study 2. Study 2 was a phase 1 dose-escalation study of orally administered docetaxel in combination with ritonavir in a weekly once-daily schedule. Patients received the approved IV formulation and/or 3 different oral docetaxel formulations: the orally administered IV formulation (drinking solution), the ModraDoc001 capsule formulation, and the ModraDoc006 tablet formulation. Initially, the soft gel capsule formulation (Norvir) of ritonavir was used. A switch to a ritonavir tablet formulation was made after the manufacturer switched to a tablet formulation during execution of the study. Docetaxel was administered in doses of 20 to $80 \mathrm{mg}$. Ritonavir was administered as a $100-\mathrm{mg}$ or 200-mg dose. For a more detailed description of these studies, see Moes et al, ${ }^{6}$ Koolen et al, ${ }^{11}$ Marchetti et al, ${ }^{12}$ and de Weger et al. ${ }^{13}$

Study 3a. Study 3a was a phase 1 dose-escalation study in which a weekly twice-daily dose of docetaxel 
formulated as ModraDoc001 capsules or ModraDoc006 tablets, together with ritonavir, was given at $\mathrm{t}=0$ and $\mathrm{t}=7$ hours. The total daily dose of docetaxel was between 40 and $80 \mathrm{mg}$ and ritonavir $200 \mathrm{mg}$. For a detailed description of Study 3a, see de Weger et al. ${ }^{14}$

Study 3b. Study 3b was a crossover study aiming at comparing the exposure of different ModraDoc formulations simultaneously administered with ritonavir. From this study only the development of ModraDoc001 was carried forward, so only PK data from this formulation were included in the current analysis. Docetaxel was administered at $40 \mathrm{mg}$. Ritonavir was administered at 100 or $200 \mathrm{mg}$. For a detailed description of Study $3 \mathrm{~b}$, see Moes et al. ${ }^{7}$

\section{Model Development}

Structural Model Development. The PK model for the coadministration of ritonavir and oral docetaxel was sequentially developed. ${ }^{15}$ In the first step, a PK model for ritonavir was developed. Transit compartment models, first-order absorption, and several complex absorption models were tested to describe the ritonavir absorption. Potential autoinhibition of metabolism of previous dosing was implemented by introducing an empirical parameter describing the relative bioavailability of the second dose versus the first dose $\left(\mathrm{F}_{2 \mathrm{nd} / 1 \mathrm{st}, \mathrm{rtv}}\right) .{ }^{16}$ More mechanistic approaches were explored, but insufficient data were available to support these models. Similarly, the effect of the formulation switch from capsule to tablet was accounted for by introducing a parameter describing the relative bioavailability of the tablet formulation versus the capsule formulation $\left(\mathrm{F}_{\text {tablet/capsule }}\right)$.

In the second step, a model for oral docetaxel, including the effects of ritonavir on oral docetaxel PK, was developed. Individual parameter estimates of ritonavir were generated from the ritonavir PK model and used as an input for docetaxel model development. ${ }^{15}$ Previously, we established a simplified semimechanistic PK model for docetaxel solely based on PK data of the IV formulation and drinking solution. ${ }^{10}$ We updated this model and used the well-stirred assumptions for hepatic clearance ${ }^{17}$ as the starting point for further development. After fixing the PK for IV docetaxel, a semiphysiological approach was explored for the oral formulations, which included separate compartments for the gut, liver, and central and peripheral compartments. In this model, the inhibitory effect of ritonavir on gut wall metabolism and hepatic metabolism of docetaxel were studied, respectively.

Statistical Model Development. Inclusion of betweensubject variability (BSV) and within-subject variability (WSV) was guided by the change of objective function value (OFV, minus twice the log likelihood), standard errors, and clinical relevance. Two types of WSV were identified. Within-day variability was considered for patients who were dosed twice-daily, and between-day variability was defined as variability between days of administration. BSV and WSV were modeled according to equation 1 .

$P_{i}=P \cdot \exp \left(\eta_{i, B S V}+\eta_{i, W S V}\right)$

where $P_{i}$ represents the individual parameter estimate for individual $i, P$ represents the typical population parameter estimate, and $\eta_{i}$ either BSV or WSV effect distributed following $N\left(0, \omega^{2}\right)$. Residual errors were described by proportional error models for both ritonavir and docetaxel, respectively (equation 2).

$C_{o b s}, i j=C_{p r e d}, i j \cdot\left(1+\varepsilon_{p, i j}\right)$

where $C_{o b s, i j}$ or $C_{p r e d, i j}$ represents, for the $i$ th subject and the $j$ th measurement, the observation or prediction. Proportional error $\epsilon_{p, i j}$ was assumed distributed following $N\left(0, \sigma^{2}\right)$.

Comparison of the Characteristics of Different Docetaxel Oral Formulations. Parameters of the PK model on absorption processes and bioavailability for different docetaxel formulations were separately estimated and compared. Furthermore, it was investigated whether there were differences in the BSV and WSV of different formulations and in the PK between once-daily and twice-daily administrations. In addition, potential saturable absorption was explored for oral docetaxel.

\section{Model Evaluation}

Model evaluation was performed throughout model building by consideration of parameter precision, plausibility of parameter estimates, goodness-of-fit diagnostics, inspection of the correlation matrix, drop of OFV with significance level of $P<.01$ (degree of freedom $[\mathrm{df}]=1, \mathrm{dOFV}>6.63 ; \mathrm{df}=2, \mathrm{dOFV}>9.21$ ) for hierarchical models, and also visual predictive checks $(n=1000)$.

\section{Simulations}

Simulation studies were performed for the ModraDoc006 tablet formulation and ritonavir tablet combination, as these formulations were selected for further clinical development. In all simulations, a dose of 100 -mg ritonavir was administered simultaneously with docetaxel.

The PK profiles of IV docetaxel in approved dosing schedules were compared to the different oral formulations. The docetaxel plasma concentration levels were simulated for oral docetaxel coadministered with ritonavir under the following dosing regimens of docetaxel: $40 \mathrm{mg}, 60 \mathrm{mg}$, and $80 \mathrm{mg}$ once daily; $20 \mathrm{mg}$ twice daily 


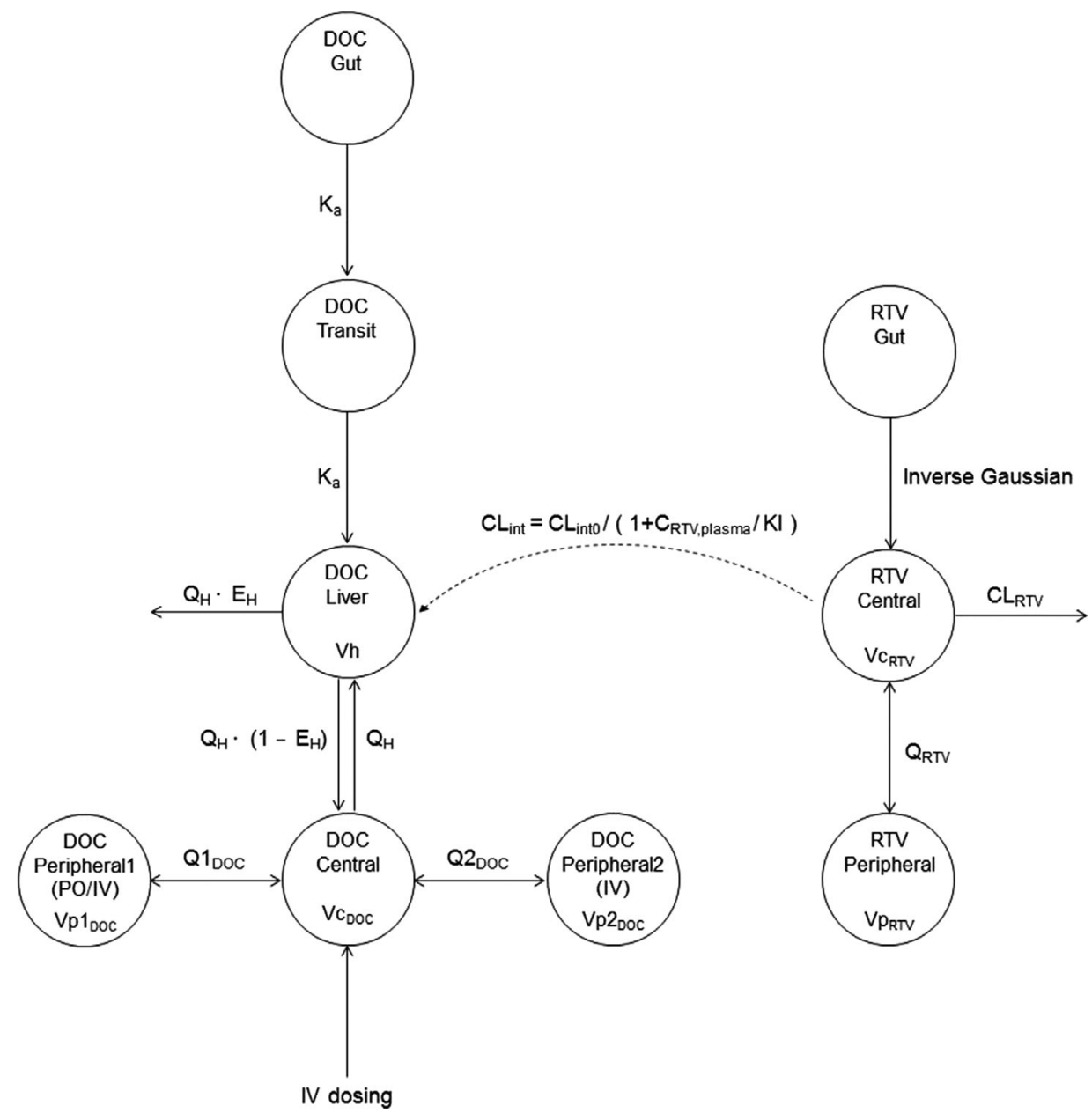

Figure I. Schematic representation of the integrated pharmacokinetic model for docetaxel and ritonavir. $\mathrm{CL}$, clearance; $\mathrm{CL}_{\text {int, }}$, intrinsic clearance of docetaxel; $\mathrm{CL}_{\text {into }}$, uninhibited intrinsic clearance of docetaxel; $\mathrm{C}_{\mathrm{RTV}}$,plasma, ritonavir plasma concentration; $\mathrm{DOC}$, docetaxel; $\mathrm{E}_{\mathrm{H}}$, hepatic extraction ratio; $\mathrm{K}_{\mathrm{a}}$, first-order absorption rate constant; IV, intravenous; $\mathrm{KI}$, inhibition constant of ritonavir on docetaxel metabolism; PO, oral; Q, intercompartment distribution; $\mathrm{Q}_{\mathrm{H}}$, hepatic blood flow; RTV, ritonavir; $\mathrm{Vc}$, central volume of distribution; $\mathrm{Vh}$, hepatic volume of distribution; $\mathrm{V}_{\mathrm{p}}$, peripheral volume of distribution. Intravenous docetaxel distributes to docetaxel peripheral compartments I and 2; oral docetaxel distributes only to docetaxel peripheral compartment I.

(20/20 mg), $30 \mathrm{mg}$ followed by $20 \mathrm{mg}(30 / 20 \mathrm{mg})$, and $30 \mathrm{mg}$ twice daily $(30 / 30 \mathrm{mg})$. For IV docetaxel, simulations were performed based on the 3 dosing regimens used in clinical practice: 3 -weekly $75 \mathrm{mg} / \mathrm{m}^{2}$ with 1 -hour infusion; 3-weekly $100 \mathrm{mg} / \mathrm{m}^{2}$ with 1 -hour infusion; and weekly $35 \mathrm{mg} / \mathrm{m}^{2}$ with 0.5 -hour infusion (assumed body surface area of $1.8 \mathrm{~m}^{2}$ ). The area under the concentration-time curve for consecutive 96 hours after administration ( $\mathrm{AUC}_{96 \mathrm{hrs}}$ ) was used to compare oncedaily and twice-daily doses. Meanwhile, the effect of the inhibition of ritonavir on the metabolism of docetaxel was assessed by comparing the docetaxel hepatic intrinsic clearance with and without coadministration of ritonavir. Because the dosing interval for IV docetaxel is usually 3 weeks, the area under the concentrationtime curve for consecutive 3 weeks after administration $\left(\mathrm{AUC}_{3 \mathrm{wks}}\right)$ was used to compare the PK profiles of IV and oral docetaxel at different dose regimens.

\section{Software}

All model estimation was performed using NONMEM (version 7.3.0; ICON Development Solutions, Manchester, UK) $)^{18}$ together with a gfortran compiler, using first-order conditional estimation with interaction. Piraña (Certara, Princeton, New Jersey) was used as graphical interface, ${ }^{19}$ and $\mathrm{R}$ (version 3.0.3) was used for preprocessing of the data, plotting, and model simulation. $^{20}$ In addition, the NONMEM toolkit $\mathrm{PsN}^{21}{ }^{21}$ and the R-packages $\mathrm{Xpose}^{22}$ and deSolve ${ }^{23}$ were used.

\section{Results}

\section{Model Development}

The schematic structure of the final model is presented in Figure 1. The parameter estimates of the final model for ritonavir and docetaxel are listed in Table 2 and Table 3, respectively. 
Table 2. Parameter Estimates of Ritonavir in the Final Pharmacokinetic Model

\begin{tabular}{|c|c|c|c|c|}
\hline Parameters & Units & Estimate & RSE (\%) & Shrinkage (\%) \\
\hline \multicolumn{5}{|l|}{ Population parameter-ritonavir } \\
\hline MAT & $\mathrm{h}$ & 8.45 & 5 & $\ldots$ \\
\hline $\mathrm{CV}$ & $\%$ & 123 & 3 & $\ldots$ \\
\hline $\mathrm{CL}_{\text {RTV }}$ & $\mathrm{L} / \mathrm{h}$ & 7.72 & 9 & $\ldots$ \\
\hline$V c_{R T V}$ & L & 23 & 15 & $\ldots$ \\
\hline $\mathrm{Q}_{\text {RTV }}$ & $\mathrm{L} / \mathrm{h}$ & 3.99 & 15 & $\ldots$ \\
\hline$V_{\text {PRTV }}$ & $\mathrm{L}$ & 17.9 & 12 & $\ldots$ \\
\hline $\mathrm{F}_{2 \mathrm{nd} / / \mathrm{st}, \mathrm{rtv}}$ & $\ldots$ & 2.25 & 7 & $\ldots$ \\
\hline $\mathrm{F}_{\text {tablet/capsule }}$ & $\ldots$ & 1.06 & 12 & $\ldots$ \\
\hline \multicolumn{5}{|l|}{ Between-subject variability } \\
\hline $\mathrm{CV}$ & CV\% & 12.8 & 22 & 45 \\
\hline $\mathrm{CL}_{\mathrm{RTV}}$ & $\mathrm{CV} \%$ & 46.7 & 13 & 25 \\
\hline$V_{c_{R T V}}$ & CV\% & 93.5 & 10 & 19 \\
\hline $\mathrm{F}$ & $\mathrm{CV} \%$ & 52.2 & 14 & 23 \\
\hline$F_{2 n d / / s t}$ & $\mathrm{CV} \%$ & 33.5 & 18 & 51 \\
\hline $\mathrm{F}_{\text {tablet/capsule }}$ & CV\% & 30 & 58 & 67 \\
\hline \multicolumn{5}{|l|}{ Within-subject variability } \\
\hline MAT & CV\% & 32.1 & 7 & $\ldots$ \\
\hline $\mathrm{CV}$ & CV\% & 22.2 & 9 & $\ldots$ \\
\hline \multicolumn{5}{|l|}{ Residual unexplained variability } \\
\hline Proportional residual error & $\mathrm{CV} \%$ & 35.2 & 2 & 12 \\
\hline
\end{tabular}

$\mathrm{CL}_{R T V}$, clearance; $\mathrm{CV}$, variability of absorption time; $\mathrm{CV} \%$, coefficient of variation; $F$, relative bioavailability; $F_{2 n d / / s t, r v v}$, relative bioavailability of the second dose to the first dose; $F_{\text {tablet/capsule, relative bioavailability of tablet to }}$ capsule; MAT, mean absorption time; $\mathrm{Q}_{\mathrm{RTV}}$, intercompartment clearance; RSE, relative standard error; $\mathrm{RTV}$, ritonavir; $\mathrm{V}_{\mathrm{C}_{\mathrm{RTV}}}$, volume of distribution of central compartment; $V_{\text {PRTV }}$, volume of distribution of peripheral compartment.

Ritonavir PK Model. A 2-compartment model with a first-order elimination process best fitted the ritonavir plasma concentrations. The absorption of ritonavir was best described by the inverse Gaussian density-input function (equation 3).

$N_{i n}=A_{D}\left[\frac{M A T}{2 \pi C V^{2} t^{3}}\right]^{1 / 2} \cdot \exp \left(-\frac{(t-M A T)^{2}}{2 C V^{2} M A T t}\right)$

where $N_{\text {in }}$ is the incoming transport flux, $A_{D}$ is the administered dose, $M A T$ is the mean absorption time, and $C V^{2}$ the term expressing the variation in absorption time. ${ }^{24}$ The second administration of ritonavir (approximately 7 hours after the first administration) showed 2.3-fold (relative standard error [RSE], 7\%) higher relative bioavailability than that of the first administration. Switching of formulation from capsule to tablet resulted in a small increment in relative bioavailability of $6 \%$ (RSE, $12 \%$ ).

Docetaxel PK Model. The final PK model of oral docetaxel was a multicompartmental model in which docetaxel after administration passed through 1 transit compartment to the liver compartment. Subsequently, docetaxel is metabolized by CYP3A4 in the liver or distributes between central and liver compartments.
Finally, docetaxel can further distribute between central and peripheral compartment(s). Two peripheral compartments best described the PK of the docetaxel IV formulation, while 1 peripheral compartment was best suited for oral formulations (Figure 1).

The influence of each oral formulation of docetaxel without ritonavir coadministration on the overall gut bioavailability $\left(\mathrm{F}_{\mathrm{G}}\right)$ was separately estimated as $F_{\text {formulation. }}$ The inhibitory effect of ritonavir on gut wall metabolism resulting in an increased $\mathrm{F}_{\mathrm{G}}$ was characterized by an empirical effect $\left(\mathrm{F}_{\text {ritonavir }}\right)$ defined as the ratio of bioavailability in combination with ritonavir vs without coadministration of ritonavir. A time-dependent accumulation of this inhibitory effect was considered on $\mathrm{F}_{\mathrm{G}}$ of the second dose relative to the

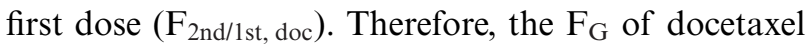
was defined according to equation 4 :

$F_{G}=F_{\text {formulation }} \cdot F_{\text {ritonavir }} \cdot F_{2 n d / 1 s t, d o c}$

Docetaxel hepatic intrinsic clearance $\left(\mathrm{CL}_{\text {int }}\right)$ was determined as a function of the uninhibited intrinsic clearance $\left(\mathrm{CL}_{\mathrm{int} 0}\right)$ and the ritonavir plasma concentration $\left(\mathrm{C}_{\mathrm{RTV}}\right.$,plasma $)$ (equation 5$)$ in which $K I$ is the inhibition constant of CYP3A4 by ritonavir. Based on well-stirred assumptions, docetaxel extraction ratio $\left(E_{H}\right)$ and hepatic bioavailability $\left(F_{H}\right)$ were defined as follows (equations 6 and 7):

$C L_{\text {int }}(t)=C L_{\text {int } 0}(t) /\left(1+C_{R T V, \text { plasma }}(t) / K I\right)$

$E_{H}(t)=\frac{C L_{\text {int }}(t) \cdot f u}{Q_{H}+C L_{\text {int }}(t) \cdot f u}$

$F_{H}(t)=1-E_{H}(t)$

Here, hepatic blood flow $Q_{H}$ was fixed at a value of $80 \mathrm{~L} / \mathrm{h}^{-1} \cdot{ }^{25}$ As only total concentrations of docetaxel (eg, free and protein bound) were available, we assumed literature-reported estimates for the fractions of unbound docetaxel $(f u)$ of $4.6 \%{ }^{26}$ The volume of the liver compartment $(V h)$ was assumed as $1 \mathrm{~L}$, which is close to the empirically determined value. ${ }^{27}$

Table 3 shows the parameter estimates of the model for IV and oral docetaxel. Based on the PK data of IV docetaxel, the $\mathrm{CL}_{\text {into }}$ was estimated at $1980 \mathrm{~L} / \mathrm{h}$ (RSE, 11\%). For oral docetaxel formulations, the second coadministration in twice-daily dosing showed an increase of $12 \%(\mathrm{RSE}, 7 \%)$ in $F_{G}$ compared to the first. Coadministration of ritonavir resulted in 3.7-fold (RSE, 28\%) higher $\mathrm{F}_{\mathrm{G}}$ than oral docetaxel without ritonavir. The KI of ritonavir was estimated at $210 \mathrm{ng} / \mathrm{mL}$ (RSE, 40\%). 
Table 3. Parameter Estimates of Docetaxel in the Final Pharmacokinetic Model

\begin{tabular}{|c|c|c|c|c|c|c|c|}
\hline \multirow{2}{*}{$\begin{array}{l}\text { Formulations of Docetaxel } \\
\text { Parameters }\end{array}$} & \multirow[b]{2}{*}{ Units } & \multicolumn{3}{|c|}{ Oral Formulations } & \multicolumn{3}{|c|}{ Intravenous Formulation } \\
\hline & & Estimate & RSE (\%) & Shrinkage (\%) & Estimate & RSE (\%) & Shrinkage (\%) \\
\hline \multicolumn{8}{|l|}{ Population parameter-docetaxel } \\
\hline First-order $\mathrm{k}_{\mathrm{a}}-$ ModraDoc00I capsule & $h^{-1}$ & 1.4 & 7 & $\ldots$ & $\ldots$ & $\ldots$ & $\ldots$ \\
\hline First-order $\mathrm{k}_{\mathrm{a}}-$ ModraDoc006 tablet & $h^{-1}$ & 0.95 & 10 & $\ldots$ & $\ldots$ & $\ldots$ & $\ldots$ \\
\hline First-order $\mathrm{k}_{\mathrm{a}}$-drinking solution & $h^{-1}$ & 1.84 & 17 & $\ldots$ & $\ldots$ & $\ldots$ & $\ldots$ \\
\hline $\mathrm{CL}_{\text {int0 }}$ & $\mathrm{L} / \mathrm{h}$ & $1980 \mathrm{FIX}^{\mathrm{a}}$ & $\ldots$ & $\ldots$ & 1980 & II & $\ldots$ \\
\hline $\mathrm{KI}$ & $\mathrm{ng} / \mathrm{mL}$ & 210 & 40 & $\ldots$ & 210 & 20 & $\ldots$ \\
\hline$V_{C_{D O C}}$ & $L$ & 119 & 12 & $\ldots$ & 5.38 & 10 & $\ldots$ \\
\hline QIDOC & $\mathrm{L} / \mathrm{h}$ & 29.8 & 6 & $\ldots$ & 15.4 & 5 & $\ldots$ \\
\hline Vpl DOC & $\mathrm{L}$ & 582 & 6 & $\ldots$ & 400 & 5 & $\ldots$ \\
\hline Q2DOC & $\mathrm{L} / \mathrm{h}$ & $\ldots$ & $\ldots$ & $\ldots$ & 5.56 & 6 & $\ldots$ \\
\hline$V_{p} 2_{D O C}$ & $\mathrm{~L}$ & $\ldots$ & $\ldots$ & $\ldots$ & 7.68 & 4 & $\ldots$ \\
\hline $\mathrm{F}_{\text {ritonavir }}$ & $\ldots$ & 3.66 & 28 & $\ldots$ & $\ldots$ & $\ldots$ & $\ldots$ \\
\hline 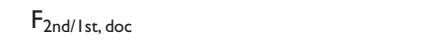 & $\cdots$ & 1.12 & 7 & $\ldots$ & $\ldots$ & $\ldots$ & $\ldots$ \\
\hline$F_{\text {formulation,ModraDoc00I }}$ & $\cdots$ & 0.18 & 23 & $\ldots$ & $\ldots$ & $\ldots$ & $\ldots$ \\
\hline$F_{\text {formulation,ModraDoc006 }}$ & $\cdots$ & 0.22 & 24 & $\cdots$ & $\cdots$ & $\cdots$ & $\cdots$ \\
\hline $\mathrm{F}_{\text {formulation,drinking solution }}$ & $\cdots$ & 0.27 & 25 & $\cdots$ & $\cdots$ & $\cdots$ & $\cdots$ \\
\hline \multicolumn{8}{|l|}{ Between-subject variability } \\
\hline $\mathrm{k}_{\mathrm{a}}$-ModraDoc00I \& ModraDoc006 & $\mathrm{CV} \%$ & 37.3 & 16 & 43 & $\ldots$ & $\ldots$ & $\ldots$ \\
\hline $\mathrm{k}_{\mathrm{a}}$-drinking solution & $\mathrm{CV} \%$ & 81.7 & 18 & 63 & $\ldots$ & $\ldots$ & $\ldots$ \\
\hline $\mathrm{CL}_{\text {int0 }}$ & $\mathrm{CV} \%$ & 38.7 & 16 & 29 & 60 & 10 & 3 \\
\hline$V_{C_{D O C}}$ & $\mathrm{CV} \%$ & 46.2 & 14 & 23 & 82.2 & 6 & 7 \\
\hline $\mathrm{F}_{\mathrm{G}}-$ ModraDoc00I \& ModraDoc006 & $\mathrm{CV} \%$ & 35.8 & 14 & 34 & $\cdots$ & $\cdots$ & $\cdots$ \\
\hline $\mathrm{F}_{\mathrm{G}}-$ drinking solution & $\mathrm{CV} \%$ & 74.2 & 15 & 59 & $\ldots$ & $\cdots$ & $\cdots$ \\
\hline \multicolumn{8}{|l|}{ Within-subject variability } \\
\hline $\begin{array}{l}\text { Between-day variability on } \\
k_{\mathrm{a}}-\text { ModraDoc00I \& ModraDoc006 }\end{array}$ & $\mathrm{CV} \%$ & 43.1 & 12 & $\cdots$ & $\cdots$ & $\ldots$ & $\cdots$ \\
\hline $\begin{array}{l}\text { Between-day variability on } \mathrm{k}_{\mathrm{a}} \text {-drinking } \\
\text { solution }\end{array}$ & $\mathrm{CV} \%$ & 39.5 & 21 & $\cdots$ & $\cdots$ & $\cdots$ & $\cdots$ \\
\hline $\begin{array}{l}\text { Within-day variability on } \\
\mathrm{k}_{\mathrm{a}} \text {-ModraDoc00I \& ModraDoc006 }\end{array}$ & $\mathrm{CV} \%$ & 50.9 & 13 & $\cdots$ & $\cdots$ & $\ldots$ & $\ldots$ \\
\hline $\begin{array}{l}\text { Between-day variability on } \\
\mathrm{F}_{\mathrm{G}}-\text { ModraDoc00I \& ModraDoc006 }\end{array}$ & $\mathrm{CV} \%$ & 29.1 & 8 & $\ldots$ & $\ldots$ & $\cdots$ & $\cdots$ \\
\hline $\begin{array}{l}\text { Between-day variability on } \mathrm{F}_{\mathrm{G}} \text {-drinking } \\
\text { solution }\end{array}$ & $\mathrm{CV} \%$ & 39.5 & 21 & $\cdots$ & $\cdots$ & $\cdots$ & $\cdots$ \\
\hline $\begin{array}{l}\text { Within-day variability on } \\
\mathrm{F}_{\mathrm{G}}-\text { ModraDoc00I \& ModraDoc006 }\end{array}$ & $\mathrm{CV} \%$ & 25.2 & 21 & $\cdots$ & $\ldots$ & $\cdots$ & $\cdots$ \\
\hline \multicolumn{8}{|l|}{ Residual unexplained variability } \\
\hline Proportional residual error & $\mathrm{CV} \%$ & 37.4 & 4 & 8 & 26.5 & 6 & 7 \\
\hline
\end{tabular}

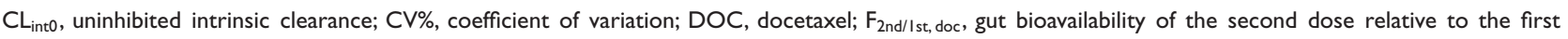

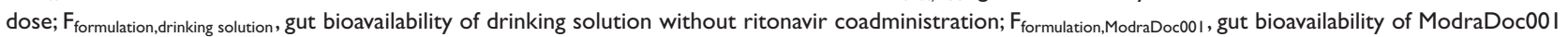

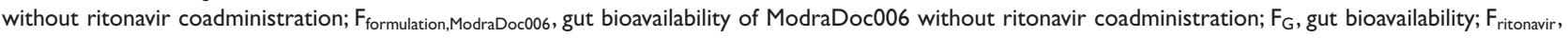
gut bioavailability in combination with ritonavir relative to without; $\mathrm{k}_{\mathrm{a}}$, absorption rate constant; KI, inhibition constant; $\mathrm{Q} \mathrm{I}_{\mathrm{DOC}}$, intercompartment clearance I; Q2 ${ }_{D O C}$, intercompartment clearance 2; RSE, relative standard error; $\mathrm{V}_{\mathrm{DOC}}$, volume of distribution of central compartment; $\mathrm{V}_{\mathrm{P}} \mathrm{I}_{\mathrm{DOC}}$, volume of distribution of peripheral compartment $1 ; V_{p} 2_{D O C}$, volume of distribution of peripheral compartment 2.

${ }^{a}$ Estimated by intravenous docetaxel and fixed in the model estimation of oral docetaxel.

We investigated whether a potential mechanismbased inhibitory effect of ritonavir on CYP3A4 could be used instead of the competitive inhibitory effect described in equation 4. This was explored by an enzyme turnover model with ritonavir inactivating CYP3A4 or accelerating the degradation rate of CYP3A4. However, these approaches failed to achieve model minimization or resulted in unreasonable parameter estimates.

The parameter estimates of the final model had adequate precision. Figures 2 and 3 show graphical model evaluations, which indicate an adequate description of the data.

Comparison of the Characteristics of Different Docetaxel Oral Formulations. The effects of the different formulations on the PK of docetaxel were estimated on absorption rate constant $\left(\mathrm{k}_{\mathrm{a}}\right)$ and $\mathrm{F}_{\mathrm{G}}$. The fastest absorption was observed for the drinking solution, followed by ModraDoc001 capsule and ModraDoc006 tablet $\left(\mathrm{k}_{\mathrm{a}}: 1.8 \mathrm{~h}^{-1}\right.$ [RSE, 17\%], $1.4 \mathrm{~h}^{-1}$ [RSE, 7\%], and $1.0 \mathrm{~h}^{-1}$ [RSE, 10\%], respectively). The drinking 


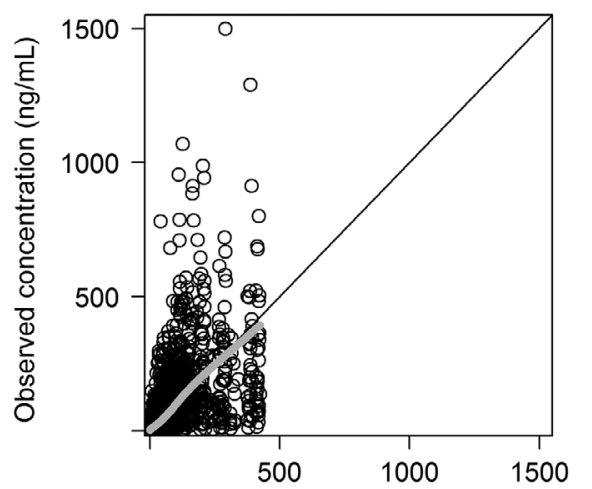

Population predicted concentration $(\mathrm{ng} / \mathrm{mL})$

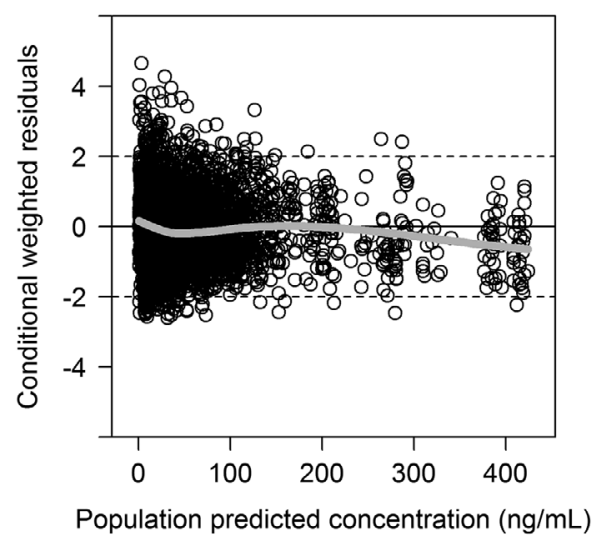

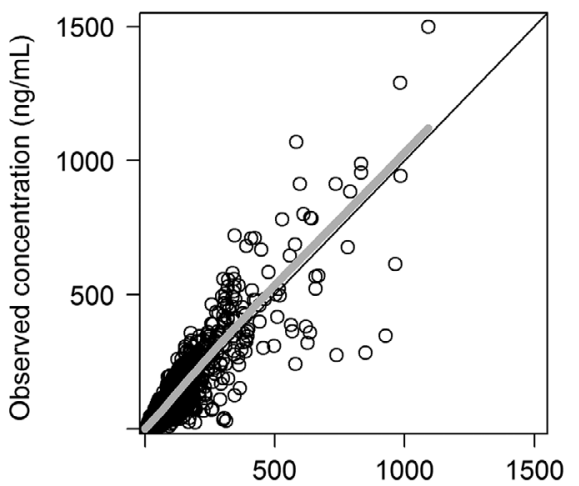

Individual predicted concentration $(\mathrm{ng} / \mathrm{mL})$

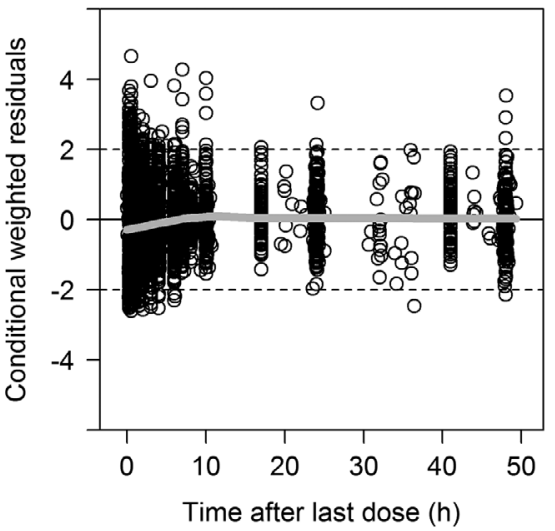

Figure 2. Goodness-of-fit plots of pharmacokinetic modelling for oral formulations of docetaxel. The plots include observed vs population predicted concentration, observed vs individual model predicted concentration, conditional weighted residuals vs population predicted concentration, and conditional weighted residuals vs time.

solution also showed the highest $\mathrm{F}_{\text {formulation }}(0.27$; RSE, $25 \%$ ) compared to ModraDoc006 (0.22; RSE, 24\%) and ModraDoc001 (0.18; RSE, 23\%).

An effect of the formulation was also found on variability. The drinking solution, compared to ModraDoc formulations, showed much higher BSV $\left(\mathrm{k}_{\mathrm{a}}\right.$ : $81.7 \%$ [RSE, $18 \%$ ] vs $37.3 \%$ [RSE, $16 \%$ ]; $\mathrm{F}_{\mathrm{G}}$ : $74.2 \%$ [RSE, $15 \%$ ] vs $35.8 \%$ [RSE, 14\%]) and higher betweenday WSV ( $\mathrm{k}_{\mathrm{a}}: 52.4 \%$ [RSE, 13\%] vs $43.1 \%$ [RSE, $12 \%]) ; \mathrm{F}_{\mathrm{G}}: 39.5 \%(\mathrm{RSE}, 21 \%$ ) vs $29.1 \%(\mathrm{RSE}, 8 \%)$ (Table 3). The between-day and within-day WSV on $\mathrm{F}_{\mathrm{G}}$ for ModraDoc formulations was $29.1 \%$ (RSE, 8\%) and $25.2 \%$ (RSE, $21 \%$ ), respectively. $\mathrm{F}_{\mathrm{G}}$ proved to be independent from dosing frequency (once-daily dosing and twice-daily dosing) and absolute docetaxel dose administered.

\section{Simulations}

Figure 4 shows the comparison of plasma concentrations of oral docetaxel administered as a single dose and 2 doses ( $\mathrm{t}=0$ and $\mathrm{t}=7$ hours) without or with ritonavir coadministration over a time span of 96 hours. The corresponding changes of docetaxel $\mathrm{CL}_{\text {int }}$ in ritonavir coadministration are also shown. For the docetaxel dosing regimen of once-daily $60 \mathrm{mg}$, the $\mathrm{AUC}_{96 \mathrm{hrs}}$ with ritonavir was 9-fold higher than docetaxel monotherapy $1204 \mu \mathrm{g} \cdot \mathrm{h} / \mathrm{L}$ vs $138 \mu \mathrm{g} \cdot \mathrm{h} / \mathrm{L}$ ); for the dosing regimen of twice-daily $30 / 20 \mathrm{mg}$, coadministration of ritonavir showed 13-fold higher $\mathrm{AUC}_{96 \mathrm{hrs}}(1458 \mu \mathrm{g}$. $\mathrm{h} / \mathrm{L}$ vs $115 \mu \mathrm{g} \cdot \mathrm{h} / \mathrm{L}$ ). A single dose of $100-\mathrm{mg}$ ritonavir maximally inhibited docetaxel $\mathrm{CL}_{\text {int }}$ to $21.8 \%$ of $\mathrm{CL}_{\text {int } 0}$ at 3.6 hours after coadministration; twice-daily $100 \mathrm{mg}$ ritonavir further inhibited the $\mathrm{CL}_{\text {int }}$ to $9.3 \%$ of $\mathrm{CL}_{\text {int } 0}$ at 10.4 hours. Docetaxel $\mathrm{CL}_{\text {int }}$ recovered to its $\mathrm{CL}_{\text {int0 }}$ after around 3 days. The $\mathrm{AUC}_{96 \mathrm{hrs}}$ of twice-daily $30 / 20 \mathrm{mg}$ of docetaxel was higher than a once-daily $60-\mathrm{mg}$ dose.

For once-daily dosing of the oral ModraDoc006ritonavir coadministration, the median $\mathrm{AUC}_{3 \mathrm{wks}}$ of 60-mg docetaxel fell within the range of $\mathrm{AUC}_{3 \mathrm{wks}}$ of the 3 regularly used dosing regimens for IV docetaxel (Figure 5). As for the twice-daily dosing, 30/30-mg docetaxel was above the range of $\mathrm{AUC}_{3 \mathrm{wks}}$ of IV docetaxel, while the 20/20 regimen is within this range.

\section{Discussion}

In the current study, we developed an integrated semiphysiological PK model for ritonavir and docetaxel. Compared to the previously described PK model of oral docetaxel, ${ }^{10}$ the current model was considerably 

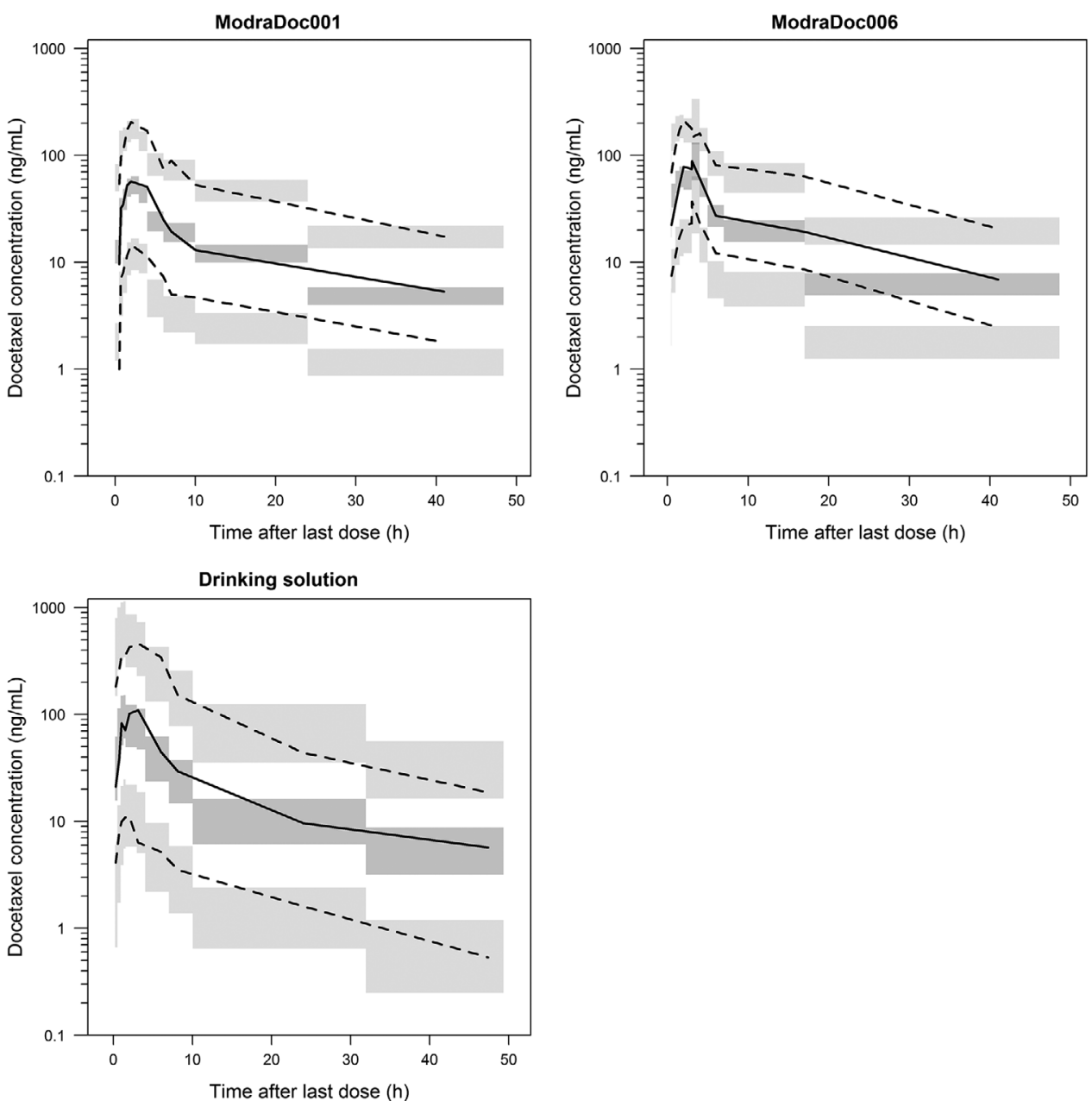

Figure 3. Visual predictive checks for docetaxel, stratified by different oral formulations $(n=I, 000)$. Solid lines and dark gray areas represent the median observed values and simulated $95 \%$ confidence intervals. Dashed lines and light gray areas represent the $10 \%$ and $90 \%$ percentiles of the observed values and $95 \%$ confidence intervals of the simulated percentiles.

improved by incorporation of novel data. First, data on newly developed docetaxel oral formulationsModraDoc001 capsule ${ }^{6}$ and ModraDoc006 tablet ${ }^{7}-$ was included, enabling further characterization of the absorption dynamics of oral docetaxel. Second, the inclusion of the data on ritonavir concentration allowed further quantification of the complex relationship between ritonavir and docetaxel PK. Third, by inclusion of the free fraction of unbound docetaxel in the wellstirred liver model, the parameters were more realistically estimated than by total docetaxel concentration.

The PK characteristics of the different docetaxel formulations were quantified. The distribution of docetaxel from the central compartment was best described by 2 peripheral compartments for the IV administration and 1 peripheral compartment for the oral formulations. As IV docetaxel is formulated in Tween80, distribution to micelles might explain this difference. The drinking solution of docetaxel was not suitable for clinical use due to its poor taste. ${ }^{5}$ Moreover, although the $\mathrm{F}_{\mathrm{G}}$ of the drinking solution was higher than the solid formulations, much higher BSV and WSV were observed (Table 3). The $\mathrm{k}_{\mathrm{a}}$ of the 2 solid formulations was comparable. The $\mathrm{F}_{\mathrm{G}}$ of ModraDoc006, however, was $16 \%$ higher than ModraDoc001. This difference is explained by the physical characteristics of these 2 formulations. The solid dispersion of ModraDoc001 was prepared by freeze drying, which did not result in a fully amorphous state, in contrast to the spray-dried formulation in ModraDoc006. The WSVs on $F_{G}$ for ModraDoc formulations were relatively low (Table 3). As a result, it was decided to continue clinical trials with the ModraDoc006 tablet. With this analysis we report on the quantification of the complex PK of this oral docetaxel formulation.

The inhibitory effect of ritonavir resulted in significantly increased docetaxel plasma exposure when coadministered, especially for the twice-daily dosing regimen (Figure 4). In the twice-daily dosing regimens, an additional boost of ritonavir on the second dose was 

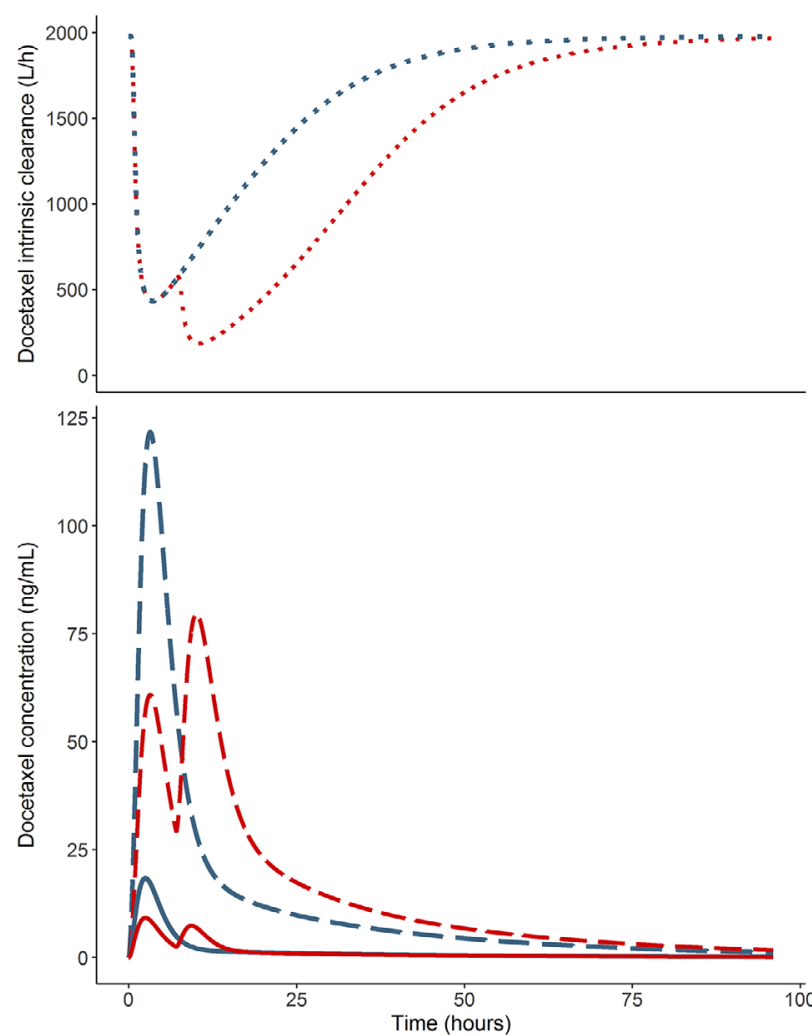

Figure 4. Simulation of population plasma concentration with corresponding intrinsic clearance of docetaxel at clinically relevant once-daily or twice-daily dosing regimens. The upper panel shows the change of docetaxel intrinsic clearance under ritonavir coadministration (dotted lines); the lower panel shows docetaxel plasma concentration without (solid lines) or with (dashed lines) ritonavir coadministration. The dosing regimens simulated in this figure are once-daily (blue graphs) $60 \mathrm{mg}$ of docetaxel and twice-daily (red graphs) $30 \mathrm{mg}$ followed by $20 \mathrm{mg}$ of docetaxel; $100 \mathrm{mg}$ of ritonavir at each intake in the coadministration.

observed, leading to a higher exposure of this regimen with the same docetaxel dose as compared to the oncedaily dosing regimen.

Coadministration of the ModraDoc formulations with ritonavir at the recommended dose reached similar docetaxel exposure $\left(\mathrm{AUC}_{3 \mathrm{wks}}\right)$ as compared to IV docetaxel (Figure 5). In comparison, $60 \mathrm{mg}$ of oral docetaxel in the once-daily dosing regimen and the regimens of $20 / 20 \mathrm{mg}$ and $30 / 20 \mathrm{mg}$ in the twice-daily dosing could result in clinically relevant plasma levels of docetaxel in patients.

In the current analysis, ritonavir plasma concentration was used to account for the inhibitory effect instead of ritonavir liver concentration, which may lead to a physiologically biased estimate of the inhibition constant KI. In addition, a mechanism-based inhibitory effect of ritonavir on CYP3A4 that is scientifically most reasonable ${ }^{28,29}$ could not be identified primarily due to the scarce PK information available $>24$ hours after administration, which would have likely allowed estimation of kinetic changes in CYP3A4 activity. Finally, clearance routes other than the liver were not considered for docetaxel. However, even with these potential limitations, the current model sufficiently describes the observation of ritonavir and docetaxel in different formulations and allowed to support the clinical development of docetaxel-ritonavir coadministration.

The modeling and simulation supported the drug development in multiple aspects. The population approach enabled the comparison of the bioavailability between once-daily and twice-daily regimens and across the wide dose range of ModraDoc formulations. The characteristics of different formulations including BSV and WSV in absorption profiles could be quantitatively compared (Table 3 ). This model-based analysis also quantified the extent of the inhibitory effect of ritonavir on the metabolism of docetaxel over time (Figure 4). The magnitude of differences on the exposure between oral docetaxel with and without ritonavir coadministration could be derived from this modelbased analysis. Here, the AUCs calculated from the PK model were not biased by differences in subjects at different dose levels in the clinical studies. Finally, the comparison of simulated AUCs between IV and oral docetaxel confirmed the clinical relevance of the plasma concentrations of different oral doses. The simulations showed that similar systemic exposure can be obtained by administration of oral docetaxel in combination with ritonavir.

\section{Conclusion}

We successfully developed an integrated semiphysiological PK model for docetaxel and ritonavir based on phase 1 studies of oral docetaxel coadministered with ritonavir. Compared to the drinking solution, oral ModraDoc formulations had much lower variability in plasma concentrations between and within patients. Coadministration of ritonavir resulted in exceedingly increased plasma concentrations and reduced inter- and intrapatient variability of docetaxel after administration of the oral formulations of ModraDoc, which confirmed the feasibility and necessity of coadministration in the clinic.

\section{Conflicts of Interest}

B.N., J.H.B., and J.H.M.S. are inventors and hold a patent on oral ModraDoc formulations. J.H.B. and J.H.M.S. are employees and shareholders in Modra Pharmaceuticals, a spinout company developing oral taxane formulations.

\section{Data Sharing}

The data that were used for this study cannot be shared. 

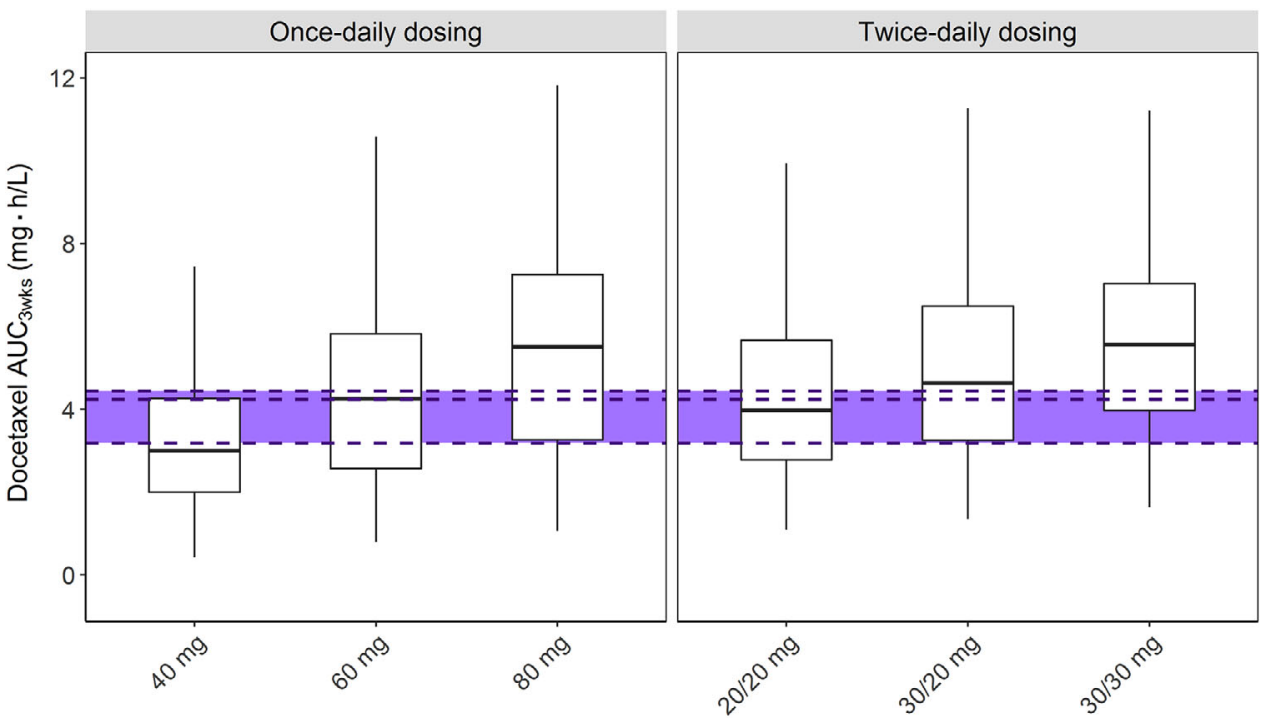

Figure 5. Comparison of docetaxel exposure between ModraDoc006 and intravenous docetaxel. The boxplot shows the median and interquartile range of simulated 3-week-time area under the concentration-time curve $\left(\mathrm{AUC}_{3 \mathrm{wks}}\right)$ for different dosing regimens of ModraDoc006 coadministered with ritonavir. The left panel shows once-daily dosing and the right panel twice-daily dosing. Three dashed lines from bottom to top represent the simulated $A \cup C_{3 w k s}$ of intravenous docetaxel at dosing regimens of 3 -weekly $75 \mathrm{mg} / \mathrm{m}^{2}, 3$-weekly $100 \mathrm{mg} / \mathrm{m}^{2}$, and weekly $35 \mathrm{mg} / \mathrm{m}^{2}$, successively. The shaded area covers the range of simulated $A \cup C_{3 w k s}$ of different dosing regimens of intravenous docetaxel.

\section{References}

1. Di Maio M, Perrone F, Chiodini P, et al. Individual patient data meta-analysis of docetaxel administered once every 3 weeks compared with once every week second-line treatment of advanced non-small-cell lung cancer. J Clin Oncol. 2007;25(11):1377-1382.

2. Camps C, Massuti B, Jiménez A, et al. Randomized phase III study of 3-weekly versus weekly docetaxel in pretreated advanced non-small-cell lung cancer: A Spanish Lung Cancer Group trial. Ann Oncol. 2006;17(3):467-472.

3. ten Tije AJ, Verweij J, Loos WJ, Sparreboom A. Pharmacological effects of formulation vehicles. Clin Pharmacokinet. 2003;42(7):665-685.

4. Bardelmeijer HA, Ouwehand M, Buckle T, et al. Low systemic exposure of oral docetaxel in mice resulting from extensive first-pass metabolism is boosted by ritonavir. Cancer Res. 2002;62(21):6158-6164.

5. Oostendorp RL, Huitema A, Rosing H, et al. Coadministration of ritonavir strongly enhances the apparent oral bioavailability of docetaxel in patients with solid tumors. Clin Cancer Res. 2009;15(12):4228-4233.

6. Moes JJ, Koolen SLW, Huitema ADR, Schellens JHM, Beijnen $\mathrm{JH}$, Nuijen B. Pharmaceutical development and preliminary clinical testing of an oral solid dispersion formulation of docetaxel (ModraDoc001). Int J Pharm. 2011;420(2):244-250.

7. Moes JJ, Stuurman FE, Hendrikx JJMA, et al. Pharmacokinetic evaluation of three oral formulations of docetaxel boosted with ritonavir: two single-drug formulations vs. a fixed-dose combination tablet. Drug Deliv Transl Res. 2013;3(3):243-251.

8. Friedrich C. A model qualification method for mechanistic physiological QSP models to support model-informed drug development. CPT Pharmacometrics Syst Pharmacol. 2016;5:43-53.

9. Koolen SLW, Van Waterschoot R a B, van Tellingen O, et al. From mouse to man: predictions of human pharmacokinetics of orally administered docetaxel from preclinical studies. $J$ Clin Pharmacol. 2012;52(3):370-380.

10. Koolen SLW, Oostendorp RL, Beijnen JH, Schellens JHM, Huitema ADR. Population pharmacokinetics of intravenously and orally administered docetaxel with or without coadministration of ritonavir in patients with advanced cancer. Br J Clin Pharmacol. 2010;69(5):465-474.

11. Koolen SLW, Beijnen JH, Schellens JHM. Intravenous-to-oral switch in anticancer chemotherapy: a focus on docetaxel and paclitaxel. Clin Pharmacol Ther. 2010;87(1):126-129.

12. Marchetti S, Stuurman F, Koolen S, et al. Phase I study of weekly oral docetaxel (ModraDoc001) plus ritonavir in patients with advanced solid tumors. J Clin Oncol. 2012;30(suppl). Abstract 2550.

13. de Weger VA, Stuurman FE, Koolen SL, et al. A phase I dose escalation study of once weekly oral administration of docetaxel as ModraDoc001 capsule or ModraDoc006 tablet in combination with ritonavir [published online ahead of print June 19, 2019]. Clin Cancer Res. 10.1158/1078-0432.CCR-17-2299.

14. de Weger VA, Stuurman FE, Hendrikx JJMA, et al. A doseescalation study of bi-daily once weekly oral docetaxel either as ModraDoc001 or ModraDoc006 combined with ritonavir. Eur J Cancer. 2017;86:217-225.

15. Zhang L, Beal SL, Sheiner LB. Simultaneous vs. sequential analysis for population PK/PD data I: best-case performance. J Pharmacokinet Pharmacodyn. 2003;30(6):387-404.

16. Eichbaum C, Cortese M, Blank A, Burhenne J, Mikus G. Concentration effect relationship of CYP3A inhibition by ritonavir in humans. Eur J Clin Pharmacol. 2013;69(10):17951800.

17. Rowland M, Tozer T. Clinical Pharmacokinetics. Philadelphia, PA: Lippincott Williams \& Wilkins; 1995.

18. Beal SL, Boeckman AJ, Sheiner LB. NONMEM user guides. https://nonmem.iconplc.com/?token=CA29B852-E463-11e9A317-005056911489. Accessed October 8, 2019. Published 1988.

19. Keizer RJ, van Benten M, Beijnen JH, Schellens JHM, Huitema ADR. Pirana and PCluster: A modeling environment and cluster infrastructure for NONMEM. Comput Methods Programs Biomed. 2011;101(1):72-79.

20. Development Core Team R. R: A Language and Environment for Statistical Computing. Vienna, Austria: R Foundation for Statistical Computing; 2008. 
21. Lindbom L, Pihlgren P, Jonsson EN, Jonsson N. PsN-Toolkita collection of computer intensive statistical methods for non-linear mixed effect modeling using NONMEM. Comput Methods Programs Biomed. 2005;79(3):241-257.

22. Jonsson EN, Karlsson MO. Xpose-an S-PLUS based population pharmacokinetic/pharmacodynamic model building aid for NONMEM. Comput Methods Programs Biomed. 1999;58(1):5164.

23. Soetaert K, Petzoldt T SR. Solving differential equations in R: package deSolve. J Stat Softw. 2010;33(9):1-25.

24. Freijer JI, Post TM, Ploeger B a., DeJongh J, Danhof M. Application of the convection-dispersion equation to modelling oral drug absorption. Bull Math Biol. 2007;69:181-195.

25. Leen E, Cooke TG, Angerson WJ, McArdle CS. Estimation of total hepatic blood flow by duplex ultrasound. Gut. 1992;33(9):1293-1294.
26. Acharya MR, Baker SD, Verweij J, Figg WD, Sparreboom A. Determination of fraction unbound docetaxel using microequilibrium dialysis. Anal Biochem. 2004;331:192-194.

27. Kan MK, Hopkins GB. Measurement of liver volume by emission computed tomography. J Nucl Med. 1979;20(6): 514-520.

28. Katzenmaier S, Markert C, Riedel K-D, Burhenne J, Haefeli WE, Mikus G. Determining the time course of CYP3A inhibition by potent reversible and irreversible CYP3A inhibitors using A limited sampling strategy. Clin Pharmacol Ther. 2011;90(5):666-673.

29. Culm-Merdek KE, von Moltke LL, Gan L, et al. Effect of extended exposure to grapefruit juice on cytochrome P450 3A activity in humans: comparison with ritonavir. Clin Pharmacol Ther. 2006;79(3):243-254. 